\title{
HIV Care Providers' Role Legitimacy as Supporters of Their Patients' Alcohol Reduction
}

\author{
Shiela M. Strauss ${ }^{*}, 1$, Corrine Munoz-Plaza ${ }^{2}$, Nelson J. Tiburcio ${ }^{2}$, Stephen A. Maisto ${ }^{3}$, \\ Joseph Conigliaro ${ }^{4}$, Marya Gwadz ${ }^{2}$, Joseph Lunievicz ${ }^{2}$ and Robert Norman ${ }^{5}$ \\ ${ }^{I}$ College of Nursing, New York University, New York, New York, USA \\ ${ }^{2}$ National Development and Research Institutes, Inc., New York, New York, USA \\ ${ }^{3}$ Department of Psychology, Center for Health and Behavior, Syracuse University, Syracuse, New York, USA \\ ${ }^{4}$ Program for Quality, Safety and Patient Rights, University of Kentucky Chandler Medical Center, Lexington, Kentucky, \\ USA \\ ${ }^{5}$ College of Dentistry, New York University, New York, New York, USA
}

\begin{abstract}
Although HIV care providers are strategically situated to support their patients' alcohol reduction efforts, many do not do so, sometimes failing to view this support as consistent with their roles. Using data collected from 112 HIV providers in 7 hospital-based HIV Care Centers in the NYC metropolitan area, this paper examines the correlates of providers' role legitimacy as patients' alcohol reduction supporters. Results indicate that providers (1) responsible for a very large number of patients and (2) with limited confidence in their own ability to give this assistance, but high confidence in their program's ability to do so, were less likely to have a high level of role legitimacy as patients' alcohol reduction supporters. Findings suggest the types of providers to target for alcohol reduction support training.
\end{abstract}

\section{INTRODUCTION}

In recent years, the focus on "prevention with positives" has increasingly urged the use of behavioral prevention interventions with HIV patients [1]. Among these interventions are those that involve HIV care providers as supporters and counselors of their patients' risk reduction efforts [2]. In view of the many HIV patients who use and abuse alcohol, one area of emphasis has been on having HIV care providers support the reduction of their patients' drinking $[3,4]$. In fact, alcohol use and abuse has been associated with more rapid disease progression, and with increased HIV-related complications [5-7]. In some cases, excess alcohol use has also been correlated with poorer adherence to ARV medications, and with increased sexual risk behaviors while under its influence, the latter exposing both HIV patients and their partners to sexually transmitted infections [8-13]. Unfortunately, in spite of these alcohol-related harms, many primary care providers in HIV care settings fail to recognize or screen for patients' excess alcohol use, or support the reduction of their patients' excess drinking $[3,14,15]$.

To assist patients' alcohol reduction efforts, HIV providers have been encouraged to implement alcohol screening and brief intervention (SBI) with their patients, an approach that has been shown to be effective in a variety of settings and with a variety of populations [16, 17]. Screening, often using a brief standardized instrument such as the Alcohol

*Address correspondence to this author at the College of Nursing, New York University, 246 Greene Street, 616E, New York, New York 10003, USA; Tel: 212.998.5280; Fax: 212.995.4359; E-mail: ss4313@nyu.edu
Use Disorders Identification Test (AUDIT), involves assessing patients for alcohol use, frequency, abuse, and dependence, and for problems caused by this use $[18,19]$. For patients whose screening indicates that they are at risk for alcohol abuse or dependence, the brief intervention that follows typically involves several 10-15 minute sessions over the course of several weeks or months. It generally incorporates patient-centered, motivational, and interactive counseling techniques that increase patients' readiness to change harmful behaviors [20]. Unfortunately, although they are effective, SBIs are frequently underutilized by providers $[21$, 22].

To better understand the underutilization of alcohol SBIs, it is helpful to examine those provider attributes that may influence this limited implementation. One such attribute is a provider's perception of her/his personal "role legitimacy" as a patient advocate for alcohol reduction, a component of HIV prevention [23]. While some HIV care providers view alcohol reduction support as consistent with their roles [24], others focus their HIV prevention activities solely on basic education regarding modes of HIV transmission, condom use, and clean needles [23]. Importantly, perceived lack of role legitimacy regarding alcohol reduction support has been shown to be related to providers' decreased likelihood of actually giving this support and of implementing alcohol SBIs $[25,26]$.

Although role legitimacy has been studied in a variety of contexts, little is currently known about those factors that contribute to providers' perceptions of the legitimacy of their roles as their patients' alcohol reduction supporters in the HIV care setting. Even the studies that have examined role 
legitimacy regarding support for patients' alcohol reduction outside of this setting have often done so by examining it in combination with role adequacy, an attribute very closely related to self efficacy [27-30]. While it is conceptually appealing to examine these two attributes in combination, it may be helpful to disentangle them in order to better understand HIV care providers' role legitimacy as patients' alcohol reduction supporters.

In addition, although provider role adequacy has been shown to be a salient correlate of role legitimacy [31], HIV care is often delivered by teams of providers in an HIV care setting rather than by isolated practitioners. These teams typically consist of both medical and non-medical providers, the latter including social workers, counselors, and case workers. Some providers in these settings may have confidence in the team's collective ability to support change in patients' behaviors, and believe that other members of their teams would be more successful and cost effective in doing so [32]. "Specialist" providers with high "collective efficacy" perceptions regarding the HIV care team, but lacking self efficacy in implementing alcohol SBIs, may particularly lack role legitimacy as patients' alcohol reduction supporters. This may especially be the case if they are responsible for large numbers of patients with limited time to spend with each one individually. Thus, to inform an understanding of the underutilization of alcohol SBIs in the HIV care setting, we examine the correlates of HIV care providers' $(\mathrm{N}=112)$ role legitimacy for implementing alcohol SBIs with their patients. Such an understanding may also suggest the types of providers who can most benefit from alcohol SBI training.

\section{MATERIALS AND METHODOLOGY}

Study participants were HIV care providers who delivered direct patient care in 7 Designated AIDS Centers (DACs) in the New York City metropolitan area in 2007. DACs are comprehensive, hospital-based, state-licensed HIV treatment centers that provide a high level of inpatient and outpatient clinical and support services, emphasize quality improvement, and use interdisciplinary teams and case management approaches. The data used in the current research were collected as part of a larger study funded by the National Institute on Alcohol Abuse and Alcoholism (NIAAA) that is evaluating a training to support HIV care providers' implementation of alcohol SBIs with their patients. The 3 hour training adapts NIAAA's Clinician's Guide for alcohol screening and brief intervention [33] for the HIV care setting. Analyses in the current research use data collected from providers at each of the participating DACs before the training took place.

All providers who consented to participate completed a 20-minute self-administered survey. The survey items had been previously tested with a group of 20 community-based HIV care providers. Five of these community-based providers participated in cognitive interviews after completing the initial version of the survey. These interviews identified items that needed editing for clarity and unintended redundancy. Following the pre-testing phase, project investigators and consultants modified some items and eliminated others.

\section{Survey Components}

In addition to responding to questions concerning their demographic characteristics, providers completed survey items about their work with HIV patients. They were asked how long they had worked with these patients, how long they were employed in their current positions, whether they worked full-time or part-time, whether they had medical credentials (i.e. were physicians, physicians' assistants, nurses, or nurse practitioners), and what was their main job at the DAC. Providers were also asked to indicate if they had specific caseloads, recognizing that those who did not have such caseloads worked with a very large number of patients. We also asked if they had attended workshops or trainings in the past year concerning motivational interviewing and/or brief interventions, and whether or not they had ever participated in a workshop that specifically addressed brief interventions for alcohol reduction. To determine providers' knowledge concerning alcohol SBIs, respondents also completed an eight item, true-false Brief Intervention Knowledge Assessment [15]. We obtained a score on this Knowledge Assessment by totaling the number of items that were correctly endorsed.

The survey also assessed their self- and collective team efficacy perceptions regarding support for patients' alcohol reduction. Eight survey items comprised an Alcohol Reduction Support Self Efficacy Scale [15]. Respondents rated (from 0 to 10 , with 10 reflecting complete confidence) the degree to which they felt confident in their ability to provide the specific type of support assessed. For example, we asked respondents to rate their confidence in helping HIV patients understand the health risks related to their drinking, in assessing HIV patients' readiness to reduce their alcohol use, and in helping HIV patients set goals regarding their alcohol reduction. A total score on the Alcohol Reduction Support Self Efficacy Scale was obtained for each respondent by totaling the scores on the individual items. The median score among the participating HIV care providers was then computed, and the group of providers was dichotomized into those scoring below the median (the "low self efficacy group") and those scoring at or above the median (the "high self efficacy group").

Eight additional survey items comprised an Alcohol Reduction Support HIV Care Team Efficacy Scale. All of these items were a direct modification of those in the Alcohol Reduction Support Self Efficacy Scale, replacing statements about self efficacy with those of HIV care team efficacy. For example, the statement in the Alcohol Reduction Support Self Efficacy Scale that reads: "I am confident that I can bring up the subject of alcohol use with my HIV+ patients," was modified to read "I am confident that STAFF at this program can bring up the subject of alcohol use with HIV+ patients." Respondents gave numerical ratings (from 0 to 10 , with 10 reflecting complete confidence) regarding the degree to which they felt confident in their HIV care team's ability to provide the specific type of support assessed. A total score on the Alcohol Reduction Support HIV Care Team Efficacy Scale was obtained for each respondent by summing the scores on each of the individual items. As was the case with the Alcohol Reduction Support Self Efficacy Scale, the median score among the participating HIV care providers was computed, and the group of providers was dichotomized into those scoring below the median (the "low collective efficacy group") and those scoring at or above the median (the "high collective efficacy group"). 
Finally, five of the survey items comprise a Role Legitimacy Scale to examine respondents' attitudes about their roles as supporters of their HIV patients' alcohol reduction efforts. This Scale served as the dependent variable for the current research. The items on the Role Legitimacy Scale were created using information gathered in informal discussions with community-based HIV care providers and DAC administrators, and from past literature regarding role legitimacy perceptions concerning alcohol reduction support among providers in a variety of contexts [34-36]. For each of the five items, respondents indicated whether they strongly disagreed, disagreed, were neutral, agreed, or strongly agreed regarding the appropriateness of their roles as patients' alcohol reduction supporters and counselors. For example, we asked respondents to indicate the extent to which they agreed that detecting and supporting alcohol reduction was appropriate for their work with HIV patients, and the extent to which they agreed that bringing alcohol into the discussion was part of the comprehensive care they should be giving to these patients. Responses were coded from 0 to 4 , with $0=$ strongly disagree to $4=$ strongly agree. A total score on the Role Legitimacy Scale was obtained for each respondent by summing the scores on each of the individual items, with higher scores exhibiting a greater sense of overall role legitimacy.

\section{Statistical Analysis}

We conducted linear regression analyses to determine the variables that explain variation in the scores on the Role Legitimacy Scale. Several types of possible predictor variables were considered, including providers' work with HIV/AIDS patients (i.e., length of time in the field, time in their current positions, whether they worked full- or part-time, whether they had a medical credential, and whether they had a specific caseload). We also considered in our analyses providers' knowledge about brief interventions, and providers' past training experiences with motivational interviewing, brief interventions, and alcohol SBIs. Finally, we created variables that divided the providers into 4 groups that cross-classified respondents based on whether they had "high" or "low" self efficacy to support their patients' alcohol reduction efforts, and whether they had "high" or "low" collective team efficacy to do so.

To determine the salient predictors of variation in the Role Legitimacy Scale scores, bivariate analyses were first conducted to determine those variables that significantly predicted this variation when considered separately. All the variables that significantly predicted variation in these scores at the .10 level or less when considered individually were then entered into a multiple linear regression model. The final multiple linear regression model includes those variables that retained their significance when the variables were considered simultaneously. We then used a linear mixed effects model to fit the same model with the addition of a random intercept for each site to assess for differences in the Role Legitimacy Scale score among the 7 DACs. We compared the linear mixed effects model to the ordinary least squares model using a boundary adjusted likelihood ratio test to assess the significance of site specific effects. All our analyses were performed using SPSS for Windows, version 15.0 and STATA version 10.

\section{RESULTS}

While a total of 115 providers completed the survey, one provider did not respond to the items that comprise the Role Legitimacy Scale. Of the remaining 114 providers that did respond to the Scale items, 112 of the scores ranged from 8 to 20 , with two extreme outliers whose scores were each " 0 " on the Role Legitimacy Scale. As these outliers greatly skewed the analyses, we dropped these two cases, and report results from the remaining 112 providers in the 7 DACs. Of these 112 providers, the number of respondents in each DAC ranged from 6 to 20, with an average of 16 providers, and a median of 18 providers.

\section{Sample Characteristics}

As can be seen in Table 1, the great majority of the 112 providers were female $(79.5 \%)$, and most were either White $(57.9 \%)$ or Black $(31.6 \%)$. About one fifth $(20.5 \%)$ were Hispanic. A large minority (43.8\%) were medically credentialed, including nurses, nurse practitioners, physicians, or physician's assistants. Most of the respondents opted to provide additional demographic information, including their age and the highest degree they obtained, and most reported their main jobs. As can be seen in Table 1, of the 91 providers who reported how old they were, their average age was 46.3 years old. Almost all of the 84 providers who reported their highest terminal education degree $(90.5 \%)$ had at least an Associate's degree. In addition, of the 53 (out of 63) respondents who were not medically credentialed and disclosed their main job at the DAC, about half (52.8\%) indicated that they were social workers or case managers.

Table 1. Characteristics of HIV Care Providers $(\mathrm{N}=112)$

\begin{tabular}{|c|c|}
\hline Characteristic & $\begin{array}{c}\text { \% or } \\
\text { Mean (Standard Deviation) }\end{array}$ \\
\hline Female & $79.5 \%$ \\
\hline \multicolumn{2}{|l|}{ Race } \\
\hline White & $57.9 \%$ \\
\hline Black & $31.6 \%$ \\
\hline $\begin{array}{l}\text { Other (Asian, Native Hawaiian/Pacific } \\
\text { Islander, More than One Race) }\end{array}$ & $10.5 \%$ \\
\hline Hispanic & $20.5 \%$ \\
\hline Age $^{\text {a }}$ & $46.3(10.4)$ \\
\hline $\begin{array}{l}\text { Education - terminal degree }{ }^{\mathrm{b}} \\
\text { High school or less } \\
\text { Associate or Bachelor's Degree } \\
\text { Master's Degree or More }\end{array}$ & $\begin{array}{l}9.5 \% \\
41.7 \% \\
48.8 \%\end{array}$ \\
\hline $\begin{array}{l}\text { Medically credentialed (nurse, nurse } \\
\text { practitioner, physician, physician's } \\
\text { assistant) }\end{array}$ & $43.8 \%$ \\
\hline \multicolumn{2}{|l|}{$\begin{array}{l}\text { Job Category of those not medically } \\
\text { credentialed }^{\mathrm{c}}\end{array}$} \\
\hline Social worker/case manager & $52.8 \%$ \\
\hline $\begin{array}{l}\text { Psychologist/ counselor/adherence } \\
\text { counselor }\end{array}$ & $\begin{array}{l}26.4 \% \\
20.8 \%\end{array}$ \\
\hline $\begin{array}{l}\text { Other (e.g. administrator, educator, } \\
\text { nutritionist, etc.) }\end{array}$ & \\
\hline
\end{tabular}


Almost all of the providers $(90.8 \%)$ worked full time in their positions, and most providers $(84.3 \%)$ were quite experienced working with HIV/AIDS patients, having worked with them in some capacity for at least 3 years. The great majority $(87.2 \%)$ had been in their current positions for at least one year. Three quarters $(75.0 \%)$ indicated that they had a specific caseload of patients for whom they were responsible.

In terms of their preparation for providing alcohol SBI support, most providers $(60.7 \%)$ indicated that they had not received training on brief interventions in the past year, nor had most providers $(61.6 \%)$ attended a training on motivational interviewing during that time frame. In addition, only about one third $(36.6 \%)$ had ever attended a training on brief interventions focusing on alcohol reduction. On average, providers scored 5.7 out of 8 correct $(71.3 \%)$ on the truefalse, Brief Intervention Knowledge Assessment.

\section{Alcohol Reduction Support Efficacy}

Total scores on the Alcohol Reduction Support HIV Care Team Efficacy Scale ranged from 23 to 80, with a mean and standard deviation of 56.8 and 14.6, respectively, and a median of 56. On the Alcohol Reduction Support Self Efficacy Scale, total scores ranged from 14 to 80, with a median of 58 , and a mean and standard deviation of 56.8 and 13.8 , respectively. The correlation between the Alcohol Reduction Support HIV Care Team Efficacy Scale and Alcohol Reduction Support Self Efficacy Scale scores exhibited a nonsignificant Pearson correlation of .129.

We created four efficacy groups based on their Alcohol Reduction Support Self Efficacy Scale scores and their Alcohol Reduction Support HIV Care Team Efficacy Scale scores.

- $\quad$ The low self efficacy, low team efficacy group (Low $\mathrm{SE}$-Low TE; $\mathrm{N}=30$ ) scored below the median on each of the two Scale scores;

- $\quad$ The high self efficacy, low team efficacy group (High $\mathrm{SE}$ - Low TE; N=27) scored at or above the median on the Alcohol Reduction Support Self Efficacy Scale and below the median on the Alcohol Reduction Support HIV Care Team Efficacy Scale;

- The low self efficacy, high team efficacy group (Low $\mathrm{SE}$ - High TE; $\mathrm{N}=23$ ) scored below the median on the Alcohol Reduction Support Self Efficacy Scale and at or above the median on the Alcohol Reduction Support HIV Care Team Efficacy Scale; and

- $\quad$ The high self efficacy, high team efficacy group (High SE - High TE; N=32) scored at or above the median on each of the two Scale scores.

\section{Role Legitimacy Scale}

The Role Legitimacy Scale score (the dependent variable in the current research), had a median of 18 and a mean and standard deviation of 17.3 and 2.7, respectively. The Scale exhibited good reliability (alpha $=.81$ ). A principal components factor analysis identified one factor, with an eigenvalue of 2.9, accounting for 58.2 percent of the variance.

\section{Explaining Variation in the Role Legitimacy Scale Score}

We examined those professional characteristics that might be associated with the Role Legitimacy Scale score for the 112 providers as a group. As can be seen in Table 2, bivariate analyses that regressed the score on the Role Legitimacy Scale identified as significant predictors $(\mathrm{p}<.05)$ the efficacy groups (with reference category the Low SE - High TE group), the score on the Brief Intervention Knowledge Assessment, and having a specific caseload. Other HIV/AIDS work-related variables (length of time in the field, time in providers' current positions, whether they worked full- or part-time, and whether they were medically credentialed); or past training experiences with motivational interviewing, brief interventions, and alcohol SBIs were not significant predictors in the bivariate analyses (nor did they approach statistical significance at $\mathrm{p}<.1$ ).

Table 2. Variables Considered in the Bivariate Analyses to Explain Variation in HIV Providers' Role Legitimacy Scale Scores Concerning Alcohol Reduction Support for Their Patients $(\mathrm{N}=112)$

\begin{tabular}{|c|c|c|c|}
\hline Variable & Beta & $\begin{array}{l}\text { Standard } \\
\text { Error }\end{array}$ & Significance \\
\hline In HIV field $\geq 3$ years & -.031 & .719 & .747 \\
\hline In current position $\geq 1$ year & .023 & .781 & .815 \\
\hline Work full time & .047 & .905 & .625 \\
\hline Have medical credential & .082 & .513 & .388 \\
\hline Have specific caseload & .246 & .572 & .009 \\
\hline $\begin{array}{l}\text { Knowledge about brief } \\
\text { interventions }\end{array}$ & .310 & .145 & .001 \\
\hline $\begin{array}{l}\text { Past training in motivational } \\
\text { interviewing }\end{array}$ & -.122 & .521 & .200 \\
\hline $\begin{array}{l}\text { Past training in brief } \\
\text { interventions }\end{array}$ & -.035 & .523 & .713 \\
\hline Past training in alcohol SBIs & .030 & .535 & .754 \\
\hline Low SE - Low TE ${ }^{a}$ & .243 & .666 & .029 \\
\hline High SE - Low TE ${ }^{a}$ & .496 & .682 & .000 \\
\hline High SE - High TE ${ }^{a}$ & .541 & .657 & .000 \\
\hline
\end{tabular}

All of the variables that were significant predictors when considered in the bivariate analyses were included in the initial ordinary least squares multiple regression model. The score on the Brief Intervention Knowledge Assessment did not retain its significance in the model when considered together with the other variables. As can be seen in Table 3, the final model includes the efficacy groups (with reference category, the Low SE - High TE group), and having a specific caseload, as significant predictors of the score on the Role Legitimacy Scale. We also fit a linear mixed effects model with random intercepts for site in order to assess for DAC clustering effects. A boundary adjusted likelihood ratio 
test comparing the ordinary least squares model with the random intercept model revealed that there was no significant site specific effect (chi square $=0.04, \mathrm{p}=0.43$ ) and produced identical coefficients and standard errors. This is equivalent to an intraclass correlation for the Role Legitimacy Scale score over site of essentially 0.0. For simplicity, only the ordinary least squares model is presented.

Table 3. Multiple Regression Model to Explain Variation in HIV Providers' Role Legitimacy Scale Scores Concerning Alcohol Reduction Support for Their Patients $(\mathrm{N}=112)$

\begin{tabular}{|l|c|c|c|}
\hline \multicolumn{1}{|c|}{ Variable } & Beta & Standard Error & Significance \\
\hline \hline (Constant) & & .59 & $<.001$ \\
\hline Low SE - Low TE $^{\text {a }}$ & .22 & .66 & .045 \\
\hline High SE - Low TE $^{\text {a }}$ & .48 & .68 & $<.001$ \\
\hline High SE - High TE $^{\text {a }}$ & .49 & .67 & $<.001$ \\
\hline Has a specific caseload & .17 & .54 & .053 \\
\hline
\end{tabular}

${ }^{a}$ Relative to the reference category: Low SE - High TE: scored below the median on Alcohol Reduction Support HIV Self Efficacy Scale and at or above the median on Alcohol Reduction Support HIV Care Team Efficacy Scale.

The results of the multiple regression analysis are depicted graphically in Figs. (1) and (2). Fig. (1) demonstrates the significantly higher scores on the Role Legitimacy Scale for the Low SE- Low TE, High SE - Low TE, and High SE - High TE efficacy groups relative to the Low SE - High TE efficacy group. Fig. (2) indicates that when the dichotomous variable, having a specific caseload, is added to the efficacy group categories, further differences in the Role Legitimacy Scale scores are illuminated, most markedly in the Low SE Low TE and Low SE - High TE efficacy groups.

\section{DISCUSSION}

Because of the high rates of alcohol use and abuse among HIV patients and the many significant harms that such use can cause, it is important that HIV care providers support their patients' alcohol reduction. Our examination of providers' role legitimacy for alcohol reduction support, a salient correlate of the provision of this support [26], revealed that role legitimacy perceptions vary according to providers' caseloads. Providers who do not have specific caseloads, and therefore have responsibility for an extremely large number of patients, are especially pressed for time. They are therefore likely to see their roles, and the reasonableness of implementing alcohol reduction support in addition to their main job responsibilities, as limited by serious time constraints [37].

Our analyses also indicate that, relative to the group of providers with low self efficacy and high HIV team efficacy for giving alcohol reduction support, having high self efficacy (regardless of the level of HIV care team efficacy) is significantly associated with higher Role Legitimacy Scale scores. This finding speaks to the extremely important role that self efficacy (or role adequacy) plays with regard to role legitimacy, and is consistent with prior research [31].

Of special interest is the fact that providers having both low self- and collective HIV care team efficacy also scored significantly higher on the Role Legitimacy Scale than did those with low self efficacy but high collective efficacy. This suggests that providers lacking confidence in their own ability and that of their HIV care team to support patients' alcohol reduction may, nonetheless, believe that alcohol reduction support is consistent with their own roles with HIV patients. They may therefore be open to learning the skills needed to implement alcohol reduction support. On the other hand, those with limited confidence in their own ability to

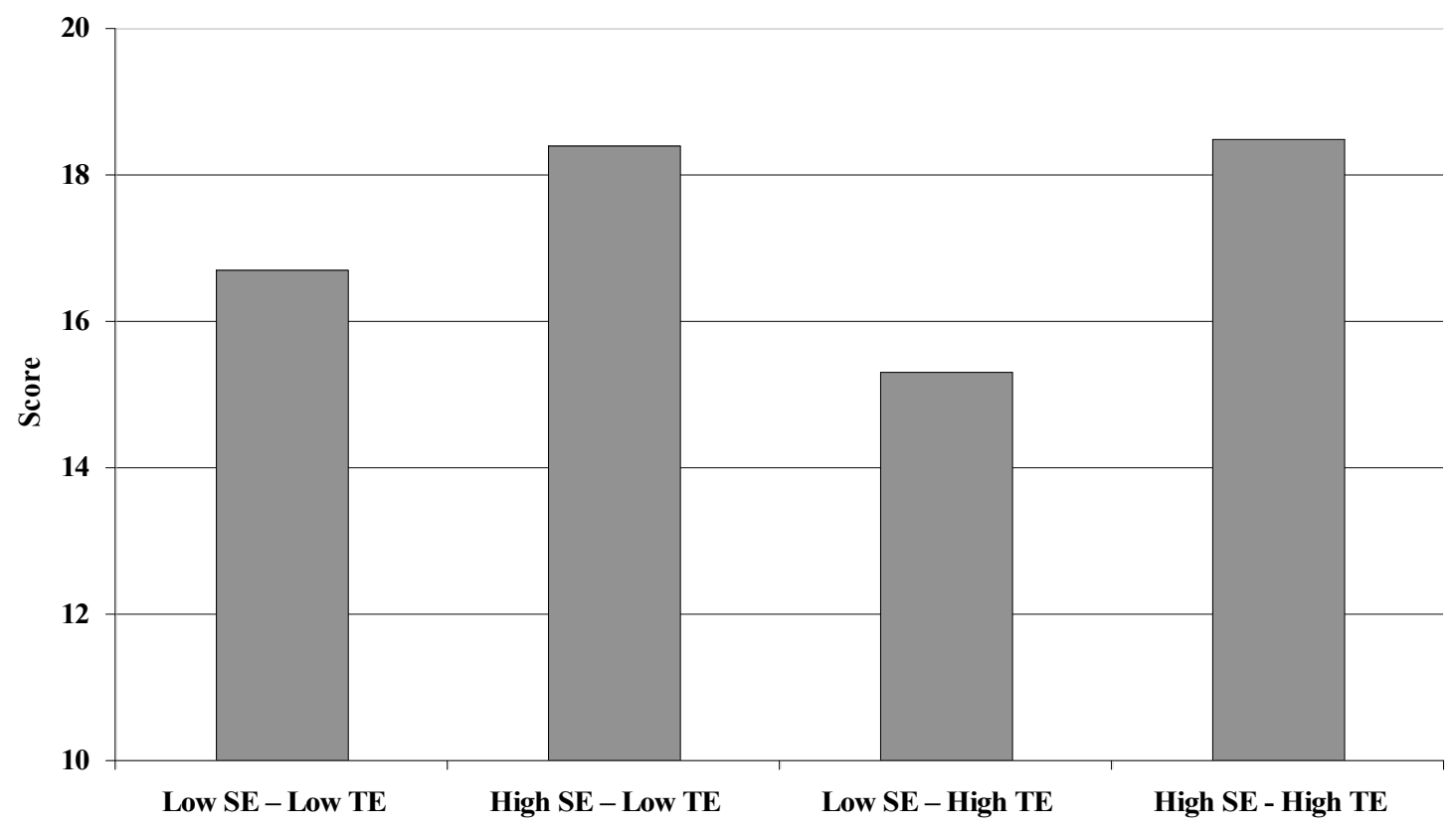

SE $=$ Alcohol Reduction Support HIV Self Efficacy Scale score $\mathrm{TE}=$ Alcohol Reduction Support HIV Care Team Efficacy Scale score

Fig. (1). Differences between the efficacy groups on the role legitimacy scale score. 


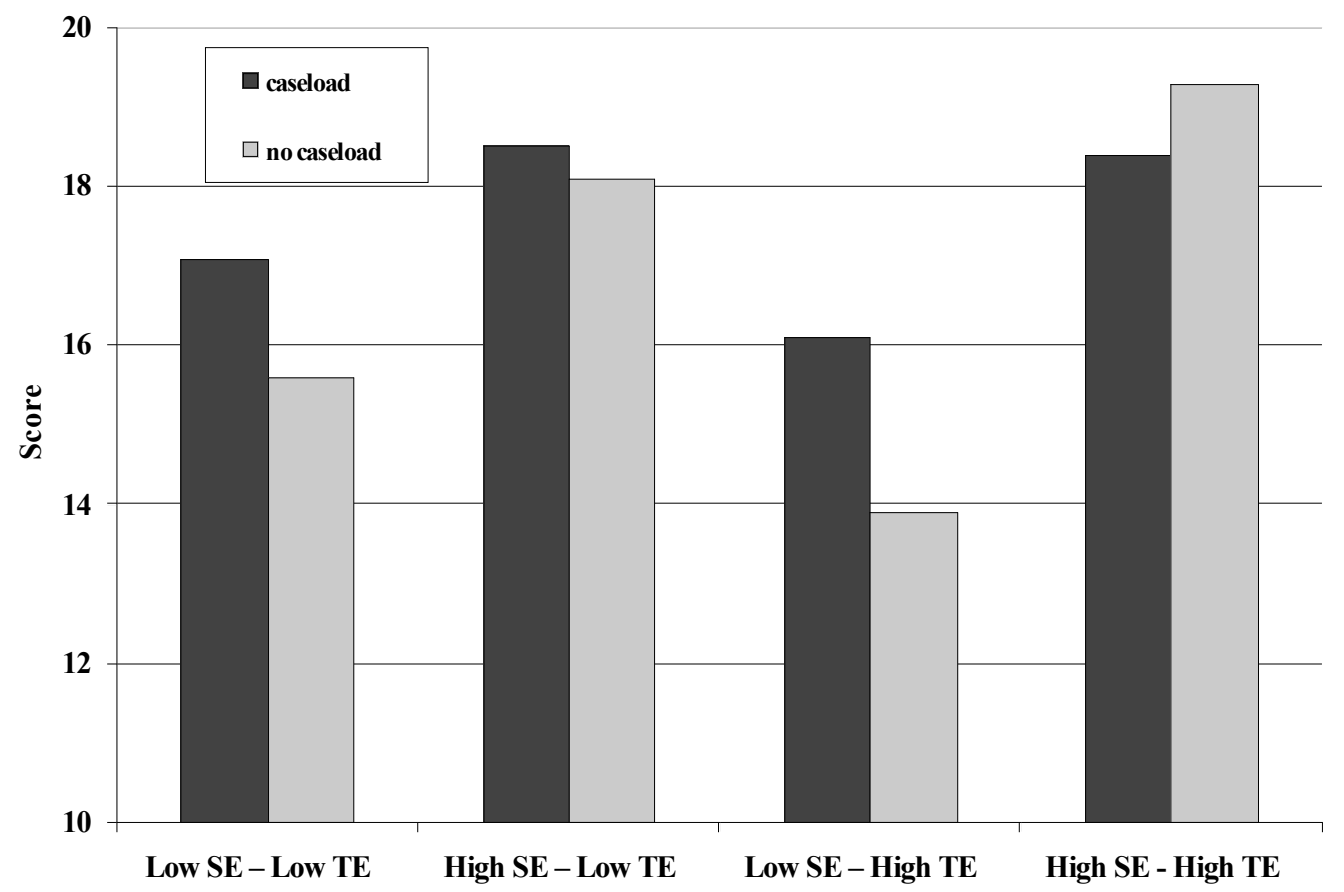

$S E=$ Alcohol Reduction Support HIV Self Efficacy Scale score

$\mathrm{TE}=$ Alcohol Reduction Support HIV Care Team Efficacy Scale score

Fig. (2). Results of the multiple regression analysis regarding the role legitimacy scale scores.

support reduction in patients' drinking, but with greater confidence in their HIV care team's ability to do so, may view other HIV care professionals as more appropriate to provide this patient support.

Some have called for the training of providers in implementing alcohol SBIs in order to ameliorate their underutilization [14]. Importantly, training in SBI implementation for providers who are secure and committed to working with problem drinkers has been found to increase SBI implementation rates [28]. On the other hand, our findings suggest that it may be less useful to offer this training to providers with limited alcohol reduction support self efficacy but high collective team efficacy. Especially with limited institutional support for their roles as alcohol reduction supporters [38], these providers may be more likely to react negatively to the tasks presented in such a training, and to experience it as a disincentive to perform the tasks [39]. In fact, Anderson and colleagues [28] found that alcohol SBI rates actually worsened after training practitioners who had low levels of initial role legitimacy, adequacy, and commitment.

In summary, as time to participate in prevention trainings is generally scarce in HIV care settings [37, 40], rather than train all providers to implement alcohol SBIs, it may be more helpful to train a targeted group who will especially benefit from the training. It is important, nonetheless, to emphasize with all HIV providers in these settings the value of having at least some member(s) of their teams offer alcohol reduction support. This approach may best serve the needs of HIV patients in these settings, while attending to the reality of limited time and resources.

We acknowledge some limitations to the research. Foremost among them is that the demographic data for the respondents were somewhat incomplete, thus precluding their use in the multiple regression analyses. We also did not ask providers about their own use of illicit or licit substances (such as cigarettes or alcohol), whose consumption may have influenced their perceptions of their role legitimacy for alcohol reduction support. In fact, research has shown that excessive drinking among medical students is associated with lower perceived relevance and frequency of alcohol counseling [41], and that a significantly smaller proportion of female physicians who reported drinking more than two drinks a week typically counseled patients about alcohol at least once a year compared with those who drank two or fewer drinks a week [42]. Because of the incompleteness in the personal data, our regression analyses examined only the relationships between the professional characteristics of the providers and their role legitimacy, for which social desirability is unlikely to have influenced written survey responses. Future research in this area should certainly take personal characteristics into account. In addition, the respondents were all providing care to HIV patients in DACs, supporting HIV patients in conjunction with other providers who have a variety of professional backgrounds (including some who may have been specifically prepared to address patients' alcohol issues). Therefore, our results may differ from other HIV care provider teams with more limited diversity in professional expertise.

\section{CONCLUSION}

In identifying the salience of caseload size and the interaction of self and collective team efficacy with regard to role legitimacy for alcohol reduction support, our findings suggest reasons for the underutilization of alcohol SBIs by some providers. They also suggest the types of providers who are especially likely to benefit from a training on alcohol reduc- 
tion support in order to provide HIV patients with much needed assistance in cutting back on their excess alcohol use.

\section{ACKNOWLEDGEMENTS}

Funding for this study was provided by the National Institute on Alcohol Abuse and Alcoholism (grant \#R21 AA016743). We also gratefully acknowledge the support of the Muriel and Virginia Pless Center for Nursing Research at the New York University College of Nursing.

\section{REFERENCES}

[1] Kalichman SC. Time to take stock in HIV/AIDS prevention. AIDS Behav 2008; 12: 333-4.

[2] Centers for Disease Control and Prevention (CDC), Health Resources and Services Administration, National Institutes of Health, and HIV Medicine Association of the Infectious Diseases Society of America. Incorporating HIV prevention into the medical care of persons living with HIV: recommendations of CDC, the Health Resources and Services Administration, the National Institutes of Health, and the HIV Medicine Association of the Infectious Diseases Society of America. MMWR 2003; 52: 1-24.

[3] Conigliaro J, Gordon AJ, McGinnis KA, Rabeneck L, Justice AC, for the Veterans Aging Cohort 3-Site Study. How harmful is hazardous alcohol use and abuse in HIV infection: do health care providers know who is at risk? J Acquir Immune Defic Syndr 2003; 33: 521-5.

[4] Galvan FH, Bing EG, Fleishman JA, et al. The prevalence of alcohol consumption and heavy drinking among people with HIV in the United States: results from the HIV Cost and Services Utilization Study. J Stud Alcohol 2002; 63: 179-86.

[5] Conigliaro J, Madenwald T, Bryant K, et al. The Veterans Aging Cohort Study: observational studies of alcohol use, abuse, and outcomes among human immunodeficiency virus-infected veterans. Alcohol Clin Exp Res 2004; 28: 313-21.

[6] Cook RT. Alcohol abuse, alcoholism, and damage to the immune system: a review. Alcohol Clin Exp Res 1998; 22: 1927-42.

[7] Meyerhoff DJ. Effects of alcohol and HIV infection on the central nervous system. Alcohol Res Health 2001; 25: 288-98.

[8] Braithwaite RS, McGinnis KA, Conigliaro J, et al. A temporal and dose-response association between alcohol consumption and medication adherence among veterans in care. Alcohol Clin Exp Res 2005; 29: 1190-7.

[9] Heckman BD, Catz SL, Heckman TG, Miller JG, Kalichman SC. Adherence to antiretroviral therapy in rural persons living with HIV disease in the United States. AIDS Care 2004; 16: 219-30.

[10] Palepu A, Raj A, Horton NJ, Tibbetts N, Meli S, Samet JH. Substance abuse treatment and risk behaviors among HIV-infected persons with alcohol problems. J Subst Abuse Treat 2005; 28: 3-9.

[11] Samet JH, Horton NJ, Meli S, Freedberg KA, Palepu A. Alcohol consumption and antiretroviral adherence among HIV-infected persons with alcohol problems. Alcohol Clin Exp Res 2004; 28: 572-7.

[12] Parsons JT, Vicioso K, Kutnick A, Punzalan JC, Halkitis PN, Velasquez MM. Alcohol use and stigmatized sexual practices of HIV seropositive gay and bisexual men. Addict Behav 2004; 29: 1045-51.

[13] Stein M, Herman DS, Trisvan E, Pirraglia P, Engler P, Anderson BJ. Alcohol use and sexual risk behavior among human immunodeficiency virus-positive persons. Alcohol Clin Exp Res 2005; 29: $837-43$.

[14] Metsch LR, Pereyra M, Colfax G, et al. HIV-positive patients' discussion of alcohol use with their HIV primary care providers. Drug Alcohol Depend 2008; 95: 37-44.

[15] Strauss SM, Tiburcio N, Munoz-Plaza C, et al. HIV care providers' implementation of routine alcohol reduction support for their patients. AIDS Patient Care STDS (accepted for publication).

[16] Fleming MF, Mundt MP, French MT, Manwell LB, Stauffacher EA, Barry KL. Brief physician advice for problem drinkers: longterm efficacy and cost-benefit analysis. Alcohol Clin Exp Res 2002; 26: 36-43.

[17] Bertholet N, Daeppen JB, Wietlisbach V, Fleming M, Burnand B. Reduction of alcohol consumption by brief alcohol intervention in primary care: systematic review and meta-analysis. Arch Intern Med 2005; 165: 986-95.
[18] Maisto SA, Saitz R. Alcohol use disorders: screening and diagnosis. Am J Addict 2003; 12[Suppl 1]: S12-S25.

[19] Reinert DF, Allen JP. The Alcohol Use Disorders Identification Test [AUDIT]: a review of recent research. Alcohol Clin Exp Res 2002; 26: 272-9.

[20] Moyer A, Finney JW, Swearingen CE, Vergun P. Brief interventions for alcohol problems: a meta analytic review of controlled investigations in treatment-seeking and non treatment-seeking populations. Addiction 2002; 97: 279-92.

[21] Fleming M, Manwell LB. Brief intervention in primary care settings: a primary treatment method for at-risk, problem, and dependent drinkers. Alcohol Res Health 1999; 23: 128-37.

[22] Fleming MF. Strategies to increase alcohol screening in health care settings. Alcohol Health Res World 1997; 21: 340-7.

[23] Morin SF, Koester KA, Steward WT, et al. Missed opportunities: prevention with HIV-infected patients in clinical care settings. J Acquir Immune Defic Syndr 2005; 36: 960-6.

[24] Lock CA, Kaner E, Lamont S, Bond S. A qualitative study of nurses' attitudes and practices regarding brief alcohol intervention in primary health care. J Adv Nurs 2002; 39: 333-42.

[25] Addy D, Skinner N, Shoobridge J, et al. Handbook for the Work Practice Questionnaire [WPQ]: A Training Evaluation Measurement Tool for the Alcohol and Other Drugs Field. Canberra: Australian Government Department of Health and Ageing, 2004.

[26] Gassman RA. Medical specialization, profession, and mediating beliefs that predict stated likelihood of alcohol screening and brief intervention: targeting educational interventions. Subst Abus 2003; 24: $141-56$.

[27] Albery IP, Heuston J, Ward J, et al. Measuring therapeutic attitude among drug workers. Addict Behav 2003; 28: 995-1005.

[28] Anderson P, Kaner E, Wutzke S, et al. Attitudes and managing alcohol problems in general practice: an interaction analysis based on findings from a WHO collaborative study. Alcohol Alcohol 2004; 39: 351-6.

[29] Anderson P, Kaner E, Wutzke S, Wensing M, Heather N, Grol R. Education, role support and the management of alcohol problems in general practice. Alcohol Alcohol 2003; 38: 597-601.

[30] Peltzer K, Pengpid S. Knowledge, attitudes and management of alcohol problems in general practice in rural South Africa. S Afr Fam Pract 2008; 50: 66. Available from http://www.safpj.co.za/ind ex.php/safpj/article/view/767/982. Accessed on November 13, 2008.

[31] Skinner N, Roche AM, Freeman T, Addy D. Responding to alcohol and other drug issues: the effect of role adequacy and role legitimacy on motivation and satisfaction. Drugs Educ Prev Polic 2005; 12: 449-63.

[32] Grodensky CA, Golin CE, Boland MS, Patel SN, Quinlivan EB, Price M. Translating concern into action: HIV care providers' views on counseling patients about HIV prevention in the clinical setting. AIDS Behav 2008; 12: 404-11.

[33] National Institute on Alcohol Abuse and Alcoholism. Helping Patients Who Drink Too Much. A Clinician's Guide, 2005. Available from http://pubs.niaaa.nih.gov/publications/Practitioner/Clinic iansGuide2005/guide.pdf. Accessed on November 13, 2008.

[34] Aalto M, Pekuri P, Seppa K. Primary health care nurses' and physicians' attitudes, knowledge and beliefs regarding a brief intervention for heavy drinkers. Addiction 2001; 96: 305-11.

[35] Aalto M, Varre T, Pekuri P, Seppa K. The role of general practitioners' working style and brief alcohol intervention activity. Addiction 2003; 98: 1447-51.

[36] Kaariainen J, Sillanaukee P, Poutanen P, Seppa K. Opinions on alcohol-related issues among professionals in primary, occupational, and specialized health care. Alcohol Alcohol 2001; 36: 1416.

[37] Grimley DM, Bachmann LH, Jenckes MW, Erbelding EJ. Provider-delivered, theory-based, individualized prevention interventions for HIV positive adults receiving HIV comprehensive care. AIDS Behav 2007; 11[Suppl. 1]: S39-S47.

[38] Cartwright AKJ, Gorman, DM. Processes involved in changing the therapeutic attitudes of clinicians toward working with drinking clients. Psychother Res 1993; 3: 95-104

[39] Pidd K, Freeman T, Skinner N, Addy D, Shoobridge J, Roche AM. From Training to Work Practice Change: An Examination of Factors Influencing Training Transfer in the Alcohol and Other Drugs Field, Canberra: Australian Government Department of Health and Ageing, 2004. 
[40] Callahan EJ, Flynn NM, Kuenneth CA, Enders SR. Strategies to reduce HIV risk behavior in HIV primary care clinics: brief provider messages and specialist intervention, AIDS Behav 2007; 11[Suppl 1]: 48-57.
[41] Frank E, Elon L, Naimi T, Brewer R. Alcohol consumption and alcohol counselling behaviour among US medical students: cohort study, BMJ 2008; 337; a2155. Accessed on December 6, 2008.

[42] Frank E, Brogan D, Mokdad AH, Simoes E, Kahn HS, Greenberg RS. Health-related behaviors of women physicians $v s$ other women in the United States. Arch Intern Med 1998; 158: 342-8.

(c) Strauss et al.; Licensee Bentham Open.

This is an open access article licensed under the terms of the Creative Commons Attribution Non-Commercial License (http://creativecommons.org/licenses/by$\mathrm{nc} / 3.0 /$ ) which permits unrestricted, non-commercial use, distribution and reproduction in any medium, provided the work is properly cited. 